\title{
Manipulative and Technological Skills Do Not Require a Slow Life History
}

\author{
Alexis J. Breen ${ }^{1 *}$, Shoko Sugasawa ${ }^{2}$ and Susan D. Healy ${ }^{2}$ \\ 'Department of Human Behavior, Ecology, and Culture, Max Planck Institute for Evolutionary Anthropology, Leipzig, \\ Germany, ${ }^{2}$ School of Biology, University of St Andrews, St Andrews, United Kingdom
}

Keywords: object manipulation, manipulative skills, technological behavior, development, life history, brain size

OPEN ACCESS

Edited by:

Patricia lzar,

University of São Paulo, Brazil

Reviewed by:

Bruna Bezerra,

Federal University of

Pernambuco, Brazil

${ }^{*}$ Correspondence:

Alexis J. Breen

alexis_breen@eva.mpg.de

Specialty section:

This article was submitted to Behavioral and Evolutionary Ecology,

a section of the journal

Frontiers in Ecology and Evolution

Received: 30 November 2020 Accepted: 20 January 2021

Published: 09 February 2021

Citation:

Breen AJ, Sugasawa S and Healy SD (2021) Manipulative and Technological

Skills Do Not Require a Slow Life History. Front. Ecol. Evol. 9:635802. doi: 10.3389/fevo.2021.635802
A recent developmental study reveals that-at least in primates-a slow life history might be a prerequisite for skilled manipulation and technological behavior. This supposition, however, demands critical evaluation because other taxa with a much shorter lifespan also exhibit dexterous object handling and material technology. By examining object-handling and nest-building data from, respectively, mice and birds, we show that a slow life history does not govern the evolution of manipulative and technological ability. More generally, we highlight the need for a comparative, cross-taxa approach to understand drivers-such as differences in life history, ecology, task complexity, and brain size - of seemingly sophisticated behavior.

\section{OBJECT MANIPULATION IN PRIMATES}

Human technological prowess is unrivaled across the animal kingdom, leading many researchers to ponder-why? To inform this question with ecological and evolutionary insights, the go-to method is to study the behavior of our closest living relatives: non-human primates. Of particular interest are the fine motor skills involved in object manipulation since such actions underpin the ability to use tools, a technological behavior we share with few species (Shumaker et al., 2011). In a recent object-manipulation study in non-human primates, Heldstab et al. (2020) contend that they have uncovered a key driver of technological behavior: a slow life history.

From 2011 to 2018, Heldstab and colleagues repeatedly visited zoos to observe when and how 128 individuals of 36 primate species handled food items (see the left panel in Figure 1), from 1 week after birth until reaching adult-level manipulation competence. Strikingly, the researchers found that the expression, in terms of both the order and the timing, of eight food-handling actions, appears almost entirely conserved across the studied primate phylogeny. For example, most species first grabbed an object with one hand early on in development (within the first several weeks), while four species-all long-lived great apes-also grabbed two separate objects simultaneously much later on in development and close to weaning (roughly 4-7 years of age). Coupling these robust developmental and life-history data, the authors conclude that complex manipulation skills and technological abilities are unlikely to evolve in species with relatively fast life histories. While this prediction may be true for primates, many short-lived species also show skilled object manipulation and material technology. A broader range of species must be considered, then, to understand the evolution of manipulative and technological ability.

\section{OBJECT MANIPULATION IN MICE AND BIRDS}

Manus digital dexterity has evolved in the majority of tetrapods, but the most adept class appears to be mammals, including short-lived rodents (Sustaita et al., 2013). House mice (Mus musculus), for example, use different one-handed and (a)synchronous two-handed foodmanipulation techniques depending on the visibility or positioning of a food item (Whishaw et al., 2017). These flexible motor actions in house mice are comparable to some of the motor actions Heldstab et al. (2020) described in primates (see the middle panel in Figure 1; and see Iwaniuk and Whishaw, 2000 for a similar conclusion). That the primates, and not the house mice, 


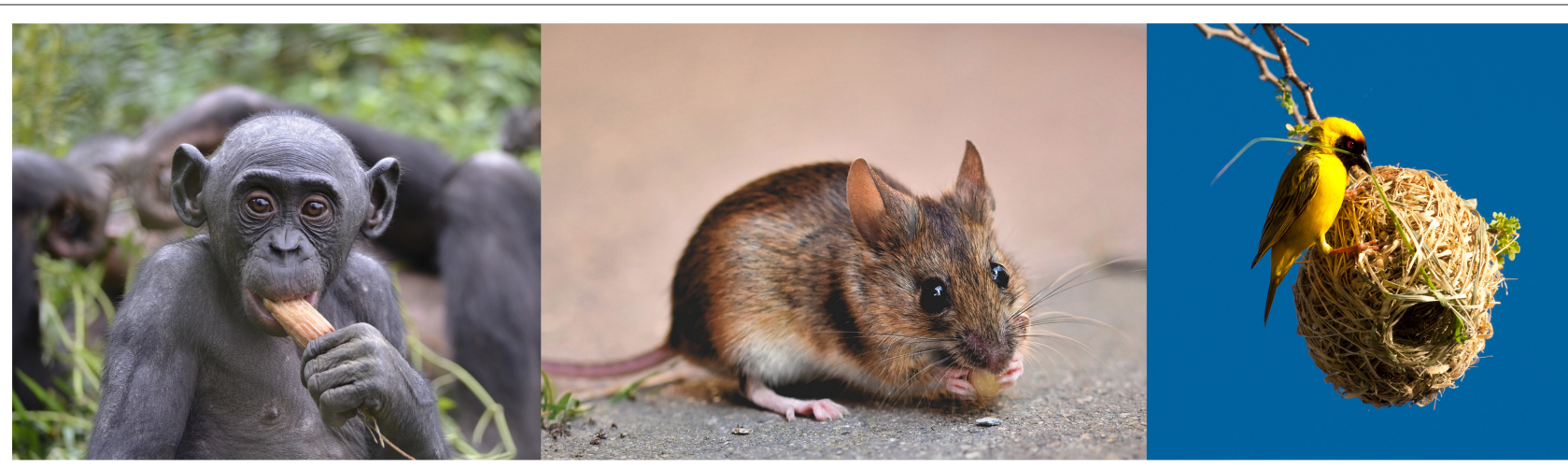

FIGURE 1 | Skilled object manipulation across three taxa. Left panel: a primate holds a piece of sugar cane with one hand. Middle panel: a mouse grasps a peanut with both hands. Right panel: a weaver bird secures fresh nest material with its bill. Image credit (left, middle, right): Christopher Krupenye; Ralph Capri; Holger Mette.

show independent-digit one-handed object manipulation, however, arguably reflects ecological rather than life-history differences. Arboreal harvest mice (Micromys minutus) pups, for instance, can move both their first and fifth digits independently to grasp horizontal plant stalks at 10 days of age; they do this, like the observed primates, following the cumulative acquisition of, in turn, digit extension and dependent-digit grasping (Ishiwaka and Möri, 1999). A similar, sequential acquisition of motor elements occurs over 3 months in nest-building by weaverbirds (Collias and Collias, 1964), a technological behavior that is phenotypically and cognitively similar to tool use (this topic is outwith the scope of the current correspondence, but for detailed discussions see: Hansell, 2000, p. 89-92; Hansell and Ruxton, 2008, Fragaszy and Mangalam, 2018, p. 196). First, juvenile weaverbirds must learn how to effectively collect strips of plant material; this involves knowing where to perch, which place to cut, what direction to tear, and how wide and long a strip should be. Next, the task of building begins: using only their bill and feet, the aspiring weavers must learn how to tuck, loop, and interlace each piece of material without the material dropping to the ground, before a hanging basket nest can take shape (see the right panel in Figure 1). Thus, taken together, these data from mice and birds show that hierarchical patterns in the development of manipulative and technological skills do not require extended ontogenetic periods; instead, 'practice' and social input appear to play the larger role, at least for nest-building birds (Collias and Collias, 1964; Walsh et al., 2010, 2011; Breen et al., 2016, 2020).

\section{BRAIN SIZE AND OBJECT MANIPULATION}

Why, then, do 36 primate species develop object manipulation skills slowly? As argued in the recent study (Heldstab et al., 2020), this pace may reflect how much time a brain needs to 'grow'. In many primate species, including humans, prolonged periods of development are associated with larger brains (Barrickman et al., 2008), potentially due, in part, to energetic costs associated with tissue growth (Isler and van Schaik, 2009). But having a big brain is not a prerequisite for skilled motor behavior: for perspective, several spider species-just like chimpanzees-actively manipulate manufactured objects to secure insect prey (Goodall, 1964; Yeargan, 1994). Indeed, it appears that in vertebrates the degree of foliation of the cerebellum, a brain region involved in motor control, is the better predictor of object manipulation skills than is brain size: not only do those primates that use tools have greater cerebral foliation than do non-tool users (Iwaniuk et al., 2009; Barton, 2012), but an increase in cerebral foliation is also associated with nest structure complexity in birds (degree of cerebral foliation: no nest $<$ platform nest $<$ cup nest; Hall et al., 2013) and variation in frogs' locomotor ability (number of cerebral folds: arboreal frogs > terrestrial frogs; Manzano et al., 2017). These kinds of comparative brain-behavior correlations, however, only hint at potential causation; for direct evidence, experimental paradigms are needed (Healy and Rowe, 2007) - a challenging prospect when brain architecture is involved.

\section{CONCLUSION}

Returning to the question of why dozens of primate species develop object manipulation slowly, the answer may sound familiar: it is simply not yet clear. But Heldstab and colleagues' study (Heldstab et al., 2020) has paved the way for promising future work on the factors underpinning technological abilities, not least because of the large developmental dataset they have made available. These detailed data on the ontogeny of object manipulation skills in primates can now be rigorously compared against similar datasets in other taxa, allowing insight into (shared and divergent) phylogenetic patterns of technological behavior more broadly. This first, albeit brief comparison using some of the rodent and avian nest-building data show that Heldstab et al.'s primate-specific result may lack generality, and that a slow life history need not explain the evolution of skilled manipulation and technological behavior.

\section{AUTHOR CONTRIBUTIONS}

AJB conceived of and wrote the manuscript, with important contributions from SS and SDH. All authors approved the final manuscript. 


\section{FUNDING}

SS was supported by the Biotechnology and Biosciences Research Council, under the grant reference BB/S01019X/1.

\section{REFERENCES}

Barrickman, N. L., Bastian, M. L., Isler, K., and van Schaik, C. P. (2008). Life history costs and benefits of encephalization: a comparative test using data from long-term studies of primates in the wild. J. Hum. Evol. 54, 568-590. doi: 10.1016/j.jhevol.2007.08.012

Barton, R. A. (2012). Embodied cognitive evolution and the cerebellum. Philos. Trans. R. Soc. B 367, 2097-2107. doi: 10.1098/rstb.2012.0112

Breen, A. J., Guillette, L. M., and Healy, S. D. (2016). What can nest-building birds teach us? Comp. Cogn. Behav. Rev. 11, 83-102. doi: 10.3819/ccbr.2016.110005

Breen, A. J., Lovie, K. E., Guerard, C., Edwards, S. C., Cooper, J., Healy, S. D., et al. (2020). Juvenile socio-ecological environment shapes material technology in nest-building birds. Behav. Ecol. 31, 892-901. doi: 10.1093/beheco/ araa027

Collias, E. C., and Collias, N. E. (1964). The development of nest-building behavior in a weaverbird. Auk 81, 42-52. doi: 10.2307/4082609

Fragaszy, D. M., and Mangalam, M. (2018). Tooling. Adv. Study Behav. 50, 177-241. doi: 10.1016/bs.asb.2018.01.001

Goodall, J. (1964). Tool-using and aimed throwing in a community of free-living chimpanzees. Nature 201, 1264-1266. doi: 10.1038/2011264a0

Hall, Z. J., Street, S. E., and Healy, S. D. (2013). The evolution of cerebellum structure correlates with nest complexity. Biol. Lett. 9, 20130687. doi: $10.1098 / \mathrm{rsbl} .2013 .0687$

Hansell, M. (2000). Bird Nests and Construction Behaviour. Cambridge: Cambridge University Press.

Hansell, M., and Ruxton, G. D. (2008). Setting tool use within the context of animal construction behaviour. Trends Ecol. Evol. 23, 73-78. doi: $10.1016 /$ j.tree.2007.10.006

Healy, S. D., and Rowe, C. (2007). A critique of comparative studies of brain size. Proc. R. Soc. B Biol. Sci. 274, 453-464. doi: 10.1098/rspb.2006.3748

Heldstab, S. A., Isler, K., Schuppli, C., and van Schaik, C. P. (2020). When ontogeny recapitulates phylogeny: fixed neurodevelopmental sequence of manipulative skills among primates. Sci. Adv. 6, eabb4685. doi: 10.1126/sciadv.abb4685

Ishiwaka, R., and Möri, T. (1999). Early development of climbing skills in harvest mice. Anim. Behav. 58, 203-209. doi: 10.1006/anbe.1999.1146

Isler, K., and van Schaik, C. P. (2009). The expensive brain: a framework for explaining evolutionary changes in brain size. J. Hum. Evol. 57, 292-400. doi: 10.1016/j.jhevol.2009.04.009

Iwaniuk, A. N., Lefebvre, L., and Wylie, D. R. (2009). The comparative approach and brain-behaviour relationships: a tool for understanding

\section{ACKNOWLEDGMENTS}

We thank James St Clair and two reviewers for constructive feedback on our manuscript.

tool use. Can. J. Exp. Psychol. 63, 150-159. doi: 10.1037/a001 5678

Iwaniuk, A. N., and Whishaw, I. Q. (2000). On the origin of skilled forelimb movements. Trends Neurosci. 23, 372-376. doi: 10.1016/S0166-2236(00)01 618-0

Manzano, A. S., Herrel, A., Fabre, A. C., and Abdala, V. (2017). Variation in brain anatomy in frogs and its possible bearing on their locomotor ecology. J. Anat. 231, 38-58. doi: 10.1111/joa.1 2613

Shumaker, R. W., Walkup, K. R., and Beck, B. B. (2011). Animal Tool Behavior: The Use and Manufacture of Tools by Animals. Baltimore: John Hopkins University Press.

Sustaita, D., Pouydebat, E., Manzano, A., Abdala, V., Hertel, F., and Herrel, A. (2013). Getting a grip on tetrapod grasping: form, function, and evolution. Biol. Rev. 88, 380-405. doi: 10.1111/brv.12010

Walsh, P. T., Hansell, M., Borello, W. D., and Healy, S. D. (2010). Repeatability of nest morphology in African weaver birds. Biol. Lett. 6, 149-151. doi: 10.1098/rsbl.2009.0664

Walsh, P. T., Hansell, M., Borello, W. D., and Healy, S. D. (2011). Individuality in nest building: do southern masked weaver (Ploceus velatus) males vary in their nest-building behaviour? Behav. Processes 88, 1-6. doi: 10.1016/j.beproc.2011.06.011

Whishaw, I. Q., Faraji, J., Kuntz, J., Mirza Agha, B., Patel, M., Metz, G. A. S., et al. (2017). Organization of the reach and grasp in head-fixed vs freelymoving mice provides support for multiple motor channel theory of neocortical organization. Exp. Brain Res. 235, 1919-1832. doi: 10.1007/s00221-017-4925-4

Yeargan, K. V. (1994). Biology of bolas spiders. Annu. Rev. Entomol. 39, 81-99. doi: 10.1146/annurev.ento.39.1.81

Conflict of Interest: The authors declare that the research was conducted in the absence of any commercial or financial relationships that could be construed as a potential conflict of interest.

Copyright (c) 2021 Breen, Sugasawa and Healy. This is an open-access article distributed under the terms of the Creative Commons Attribution License (CC BY). The use, distribution or reproduction in other forums is permitted, provided the original author(s) and the copyright owner(s) are credited and that the original publication in this journal is cited, in accordance with accepted academic practice. No use, distribution or reproduction is permitted which does not comply with these terms. 